\section{Assessment on Learning Management Systems for Open and Distance Learning of Engineering Courses}

\author{
Raudhah Othmana, Siti Nur Mariani Mohd Yunosa, Muhd Nazrul \\ Hisham Zainal Alam ${ }^{\text {* }}$ \\ ${ }^{a}$ Faculty of Mechanical and Manufacturing Engineering, Universiti Tun \\ Hussein Onn Malaysia, 86400 Parit Raja, Johor, Malaysia. \\ ${ }^{b}$ School of Chemical \& Energy Engineering, Faculty of Engineering, \\ Universiti Teknologi Malaysia, 81310 UTM Skudai, Johor, Malaysia. \\ *nazrulhisham@utm.my
}

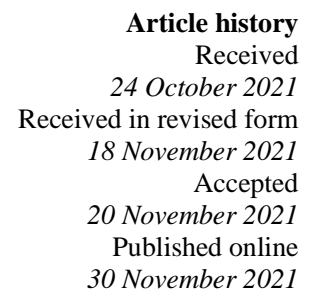

30 November 2021

\begin{abstract}
Engineering education in higher learning institute faces new challenges due to the rise of COVID-19 cases whereby classes have to be conducted online. In this regards, the use of learning management systems (LMS) are imperative for open and distance learning (ODL). The aim of this paper is to assess ODL using such LMS platform. Study was conducted in Faculty of Mechanical and Manufacturing Engineering, Universiti Tun Hussein Onn Malaysia where it involved a total of 51 academic staff. A quantitative method using online questionnaire was applied to evaluate main preferences of LMS for ODL, main purposes of LMS and issues arises from using such LMS platform. Results show that a variety of LMS has been utilized to support the ODL and majority of the academician showed positive feedback on the usefulness of such LMS. The only main concerns from the educators are plagiarism from the students that could create doubts and none trustworthy results on their performances. Otherwise, LMS is indeed an essential platform for ODL and must be encouraged to all educators such that it can be further improved and continuously utilized in the future.
\end{abstract}

Keywords: Online education; open and distance learning; learning management systems; engineering education. .

\section{Introduction}

The continuing spread of COVID-19 disease has affected and changed the landscape of higher education atmosphere. Due to this pandemic, in class lectures and/or face-to-face education is no longer an option as it will only increase the risk of COVID-19 infection. Moreover, in some countries (including Malaysia), the government has imposed a nationwide lockdown or Movement Control Order (MCO) where it limited the operation of many sectors - this include education. Engineering courses in higher learning institute suffered critically from this situation (Lubiński and Tama, 2021). Globally, teaching and learning activities must now be implemented virtually where many regarded it as the open and distance learning (ODL) education. ODL is the current trend in education as opposed to the conventional face-to-face lectures.

Since the spread of COVID-19 which began in early 2020, various types of Learning Management Systems (LMS), has been developed to support teaching and learning activities associated to ODL. LMS is generally referred to a web-based content management systems (or software) that enables educators to manage, plan, share notes, and conduct a variety of learning activities such as lecturing, quizzes, exam, etc. in an online medium (Aldiab et al., 2019) and thus, ideally suited for ODL purposes. Utilization of LMS for ODL is heavily relies on technology particularly electronic devices namely mobile phone, computer, and/or tablet as a medium of communication between lecturers and students. ODL can be conducted through various ways such as video conferencing, open online course, hybrid learning, computers based and fixed time online course where all can be executed via LMS (Chung, 2013). In one hand, the synchronous ODL can be conducted via video conference and chatroom and it provides direct interaction between the students and lecturers. On the other hand, asynchronous ODL provides indirect interaction as it happens not in real time and more flexible as student have options to study the materials provided by the lecturers independently at their own time and pace.

While some may have adapted to this abrupt change but many has raised concerns on two major aspects. Firstly, is on the readiness and acceptance of the faculty members as well as the students on such ODL environment. Secondly, on the effectiveness of the deliverables of lectures through online (internet) communication via LMS particularly on the development of important student skill set (the cognitive, psychomotor and affective domains). Delivering a face-to-face lectures in engineering courses is a challenging task. Often students have issues understanding complex theory and lecturers do need to go to the certain extent to provide a satisfactory explanation for it. Indeed, the use of LMS offers many options for the educators in conducting 
ODL but can LMS be sufficiently applied in ODL to provide students and lecturers the same satisfaction as the traditional lecturing environment.

Clearly, utilization of LMS for ODL in engineering courses requires continuous assessment. Therefore, in present paper, assessment was conducted to highlight the following questions:

1) What are the most preferred LMS for ODL in engineering courses?

2) What are the main purposes of LMS in ODL?

3) What are the issues faced by lecturers in using LMS for ODL?

The study was conducted in Faculty of Mechanical and Manufacturing Engineering, Universiti Tun Hussein Onn Malaysia (UTHM). A questionnaire-based survey were created to get input for the study where in involved all academic staff of the faculty. Results attained from the survey conducted were discussed in details. Additionally, the paper also includes a brief review on previous studies.

\section{Literature review}

At the early stage of worldwide movement to online learning during pandemic, many studies have been conducted to assess ODL readiness among students (Chung et al., 2020; Ismail et al., 2020; Mathew \& Chung, 2020) and the challenges faced by lecturers in implementing ODL (Irfan et al., 2020; Simamora et al., 2020; Simanjuntak \& Panjaitan, 2021). Selvanathan et al. (2020) have highlighted that there are still many room for improvement in the online learning and teaching, particularly in terms of the quality of the interaction and instruction delivered to the students. In another study, Musa et al. (2020) suggest that one of the key elements to make ODL effective is student's motivation and this will also lead to student's performance.

Despite some concerns over typical issues found in LMS namely unfriendly interface, glitches, inability to link to third party tools, etc. (Irfan et al., 2020), LMS has grown in popularity to support the execution of ODL. The LMS allows lecturers to manage their classes and performing administrative tasks which include providing online class materials, conducting discussions and assessments, task evaluation and others online activities (Saidi et al., 2021). A study on the student readiness towards integration of LMS into their learning indicates that students who were computer literate were more ready to engage in LMS compared to those who are computer phobia (Fashina \& Adisa, 2020).

In terms of infrastructure, Ismail et al. (2020) mention that reliable network infrastructure is important to ensure the delivery of the online learning is not interrupted and the quality is maintained. Therefore, it is crucial for the universities to increase their server bandwidth to support online teaching and learning through LMS.

There are many choices of free and paid LMSs to choose from such as Google Classroom, Edmodo,
Moodle, Schoology and university's e-learning portals such as Blackboard, uFuture and Spectrum. While the freely available LMS can be adopted by any educators, some universities also have developed their own platform. However, further improvement in the university's LMS platform is highly needed to have efficient and effective adoption of this system (Alshira et al., 2021).

Meanwhile, an extensive review on the use of free web-based Google Classroom during the spread of COVID-19 has been given by Okmawati (2020). A study conducted by Irfan et al. ( 2020) at 3 universities in Indonesia suggests that Google Classroom, followed by Edmodo, are the most adopted LMS in teaching and learning as they are easier to use compared to the available LMS on campus. The university's LMS is found to be less attractive to lecturers since the functions are limited. Similarly, Saidi et al. (2021) shows that the most popular LMS among lecturers and students at public and private higher learning institutions in Malaysia is also Google Classroom, and this is followed by the university's very own LMS. In general, both studies indicated that lecturers and students showed positive perception on the use of Google Classroom for ODL. Since UTHM has its own LMS, it is within this perspective that this study aims to investigate Faculty of Mechanical and Manufacturing Engineering academic staffs' perspective and preference on the various LMS as a platform on ODL, particularly in conducting online assessments.

\section{Methodology}

In this study, a quantitative approach was implemented through the use of online questionnaire. The questionnaire has a total of 13 questions that was partly adopted from Ismail et al. (2020) and Aldiab et al. (2019) and is divided into three categories namely Section A, B and C. Section A of the questions was structured to capture the demographic information of the respondents. This include the duration of their working experience and the type of program (undergraduate and/or post graduate) they have been assigned on in the last three (3) semesters. In Section $\mathrm{B}$, multiple choices questions were formed to gather the respondent's feedback on the learning management systems (LMS) for open and distance learning (ODL). These include their preferred communication method and live meeting platform with students for ODL. Questions about purposes of using LMS for ODL are also included in this section. There are 8 choices (questions) and respondents are allowed to select more than one answer (i.e. anywhere from 1 up to 8 choices given). The last section (Section C) comprises the ranking type questions about utilization of the most preferred LMS platform for assessment in ODL which included continuous assessments and evaluation of final examinations. Respondents were required to compare each options in the order of preferences with 3 is the most preferred method, 2 neutral and 1 is the least preferred method. 
Section $\mathrm{C}$ also comprises question about issues on the use of LMS for assessment of ODL. These issues are common in LMS and respondents were required to choose which one of these issues are the most pressing ones for them in using LMS for ODL.

Total participants (respondents) for this study is 51 where respondents are academicians (i.e. lecturers and professors) in Faculty of Mechanical and Manufacturing Engineering, Universiti Tun Hussein Onn Malaysia (UTHM). The questionnaire was administered using a Google form platform and was sent as links to the respondents via WhatsApp. Respondents were required to complete each questions on the survey given within the period of one week. Data attained were assessed and discussed in the following section.

\section{Results and Discussion}

This section presents and discusses the results of the survey, which consists of lecturer preferences of LMS for ODL, purposes in using LMS for ODL among the lecturers, and issues faced by lecturers in the use of LMS for assessment of ODL.

\section{Preferences of LMS for ODL}

Figure 1 shows the distribution of the lecturers in Faculty of Mechanical and Manufacturing Engineering, UTHM according to their working experience as academician and the type of programs they have been assigned on in the last three (3) semesters. The survey revealed that out of 51 respondents, $54 \%$ of the faculty members have at least 15 years of working experience between them, about $36 \%$ have experience as academician for 6 to 15 years and $10 \%$ of the respondents have less than 5 year working experience as lecturers. Most of the faculty members i.e. up to $62 \%$ of them were assigned to teach undergraduate courses where else about 38\% have been assigned to handle courses in both postgraduate and undergraduate programs. The results attained are in agreement with the fact that experience members of the faculty are obviously professors who has vast experience in lecturing and has also been trusted to handle advance engineering course for the postgraduate program.

Nevertheless due to COVID-9 pandemic, lecturers are forced to use technological platform such as LMS to facilitate their teaching and learning activities. This completely change the education paradigm. In the traditional lecturing system, often skilled professors are popular amongst the students as education and evaluation are highly depending on the educators experience and knowledge. However, in virtual environment i.e. online based education, this may not be case. Quality of teaching is now depending on the educator capacity to apply various online tools in their teaching and learning activities. Junior faculty can easily become the experts and preferences in ODL simply because he/her readiness to accept the change and started exploring a variety of LMS platform.
Indeed, junior faculty maybe a fast learner when it comes to adaptation of new technological tools but experience professors are a great speaker and motivator which is also valuable in online learning medium. Clearly, apart from continuous technical support from help desk, mixture of junior members and experience staff in a department/faculty holds a pivotal role in this matter in order to ensure a smooth transition from the traditional lectures environment into ODL regardless of faculty member background.

(A)
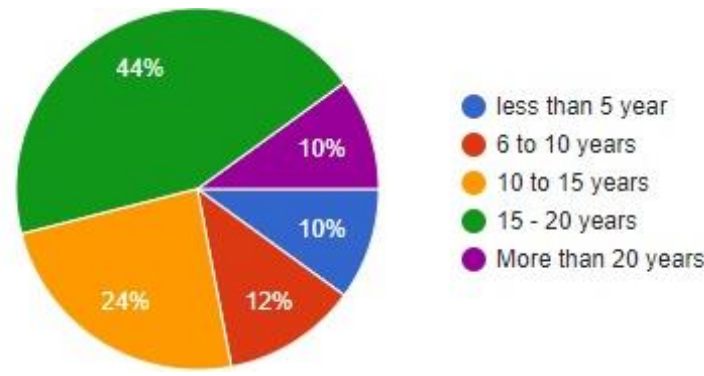

(B)

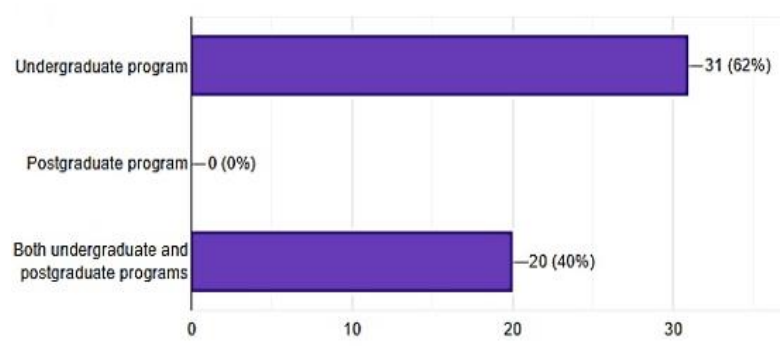

Figure 1. (a) Respondents working experience as academician and (b) the type of programs they have been assigned on.

Figure 2 presents the information about respondent's preferences on the type of communication method and live meeting session for ODL. As shown in Figure 2(a), majority i.e. approximately $90 \%$ of the academic staff preferred to use WhatsApp medium for online communication with the students where else nearly $10 \%$ of the academician preferred to engage the students using Telegram platform. This is clearly an obvious choice for the lecturers as WhatsApp medium is among the most popular mobile messenger application in the world (Yusoff et al., 2021). Plus no additional training is required as both lecturers and students are already exposed to such technology in their daily online communications. Furthermore, such an online mobile application also enable lecturers to create specific group for any academic courses for information sharing which is very beneficial especially to initiate the first lecture in the beginning of every semester. Contrary to emails or Facebook, WhatsApp medium helps lecturers to engage in active communication with the students at any time i.e. within the boundary of academician working hours and thus, keep them focus and motivated in enduring ODL throughout the semester. 
Based on the results presented in Figure 2(b), although Zoom and Microsoft Teams are among the best video conferencing tools, many of the faculty members (i.e. $92.2 \%$ out of the total 51 respondents) preferred to utilize Google Meet as their platform for live meeting (online lectures) with the students. Google Meet is the main preference probably due to several reasons. Firstly, many of the lecturers is already using Google as their main internet search engine and live streaming (or lecturing) via Google Meet is sort of embedded in their mind settings. Secondly, Google Meet is also secure and easy to use whereby no installer is needed and academician can initiate online lecturers directly from the internet browsers with only couple of steps. Finally, Google also couples various attractive online services for teaching and learning such as google classroom, google drive, etc. with can be couple with online meetings via Google Meet. This sort of features truly attracts the academician in managing their ODL activities (Uziak et al., 2018).

(A)

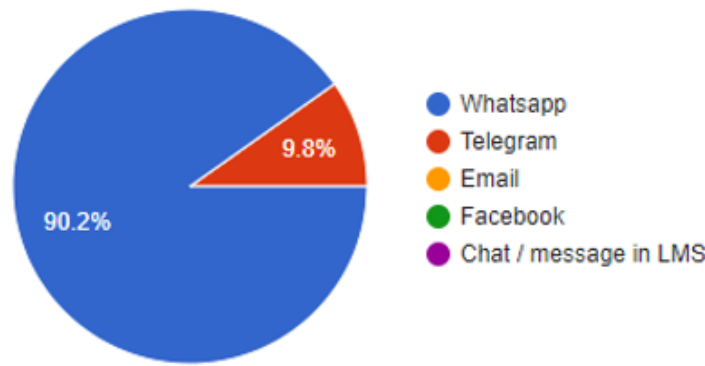

(B)

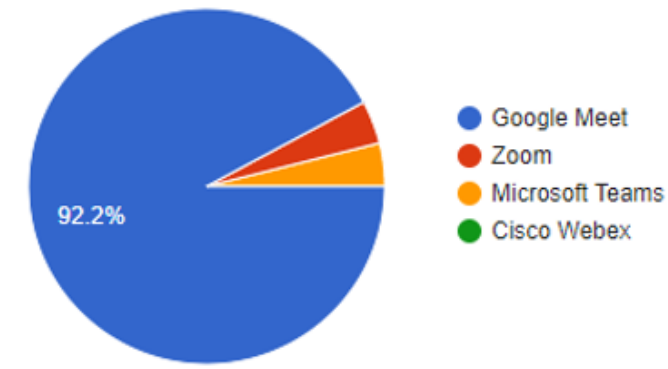

\begin{abstract}
Figure 2. Respondent's preferences on (a) communication method and (b) live meeting platform for ODL.
\end{abstract}

Figure 3 illustrates the respondent's preferences on type of LMS for their online teaching and learning activities. It was found that $54.9 \%$ of the respondents choose to work with UTHM very own LMS namely Author UTHM, 35.3\% preferred Google Classroom medium, about $4 \%$ utilized Microsoft Teams and only a small number amongst the academician (i.e. between 3-5\%) would opted for gaming based LMS such as Kahoot, Moodle, and Edmundo for their online lecturing medium. It is common nowadays that every higher learning institute has their very own LMS. This is essential for assigning courses (teaching loads) to lecturers and a main platform for lecturers to share course materials with the students. In UTHM, such LMS for teaching and learning activities are called Author
UTHM. Author UTHM has been used by academic staff even before the pandemic. Its usefulness becomes even more pronounced due to the pandemic since everything has to be done online. Additionally, new features have been added into Author UTHM platform to allow lecturers to form and/or conduct their own blended learning strategy (Sanudin et al., 2019). So, it was to be expected that many of our academician still relying mainly on Author UTHM for ODL as they have indeed familiarized themselves with such LMS platform. Alternatively, Google Classroom is also a good LMS platform for ODL. Some of our faculty members have extensively utilized its usefulness and was used as complimentary in their online lecturers to support what is lacking in Author UTHM. The gaming based LMS is clearly still in exploratory phase for our staff and not many are keen to create such gaming environment in their online teaching and learning activities. Plus, it is not so straight forward to execute and it requires proper planning and structure (Zainal Alam, 2020). Nevertheless, the variety tools used for teaching and learning indicated the level of creativity of the lecturers in our department in conducting their ODL. It has also been reported that the use of various online teaching tools are essential for student cognitive development in their education (Zainal Alam and Zakaria, 2021).

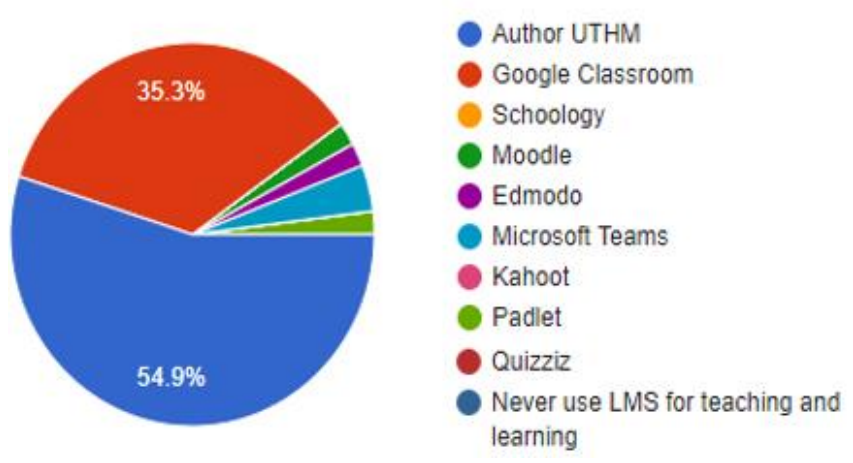

Figure 3. Respondent's preferences on LMS for online teaching and learning activities.

\section{Main Purposes of LMS for ODL}

The data in Figure 4 shows the responses of the faculty members on the main purposes in using LMS platform for ODL activities. In this particular questionnaire, participants are allowed to select any of the options provided in the survey. Most LMS platform contains various administrative tools and a variety of interactive features to support online learning (AlHunaiyyan et al., 2020; Kraleva et al., 2019). However, in accordance to the results in Figure 4, out of 8 of the items asked, majority i.e. more than $90 \%$ of the academician in our faculty utilized LMS mainly for administrative purposes. These include sharing of course information (98\%), uploading of course materials $(96.1 \%)$, and creating links to assign and retrieval of student assignments (94.1\%). Obviously, it 
is important to share the details of the taught course to the students to make sure the students are aware of what they are going to learn, what they need to achieve at the end of the course from the course learning outcomes and the assessments to be carried out and how they are evaluated.

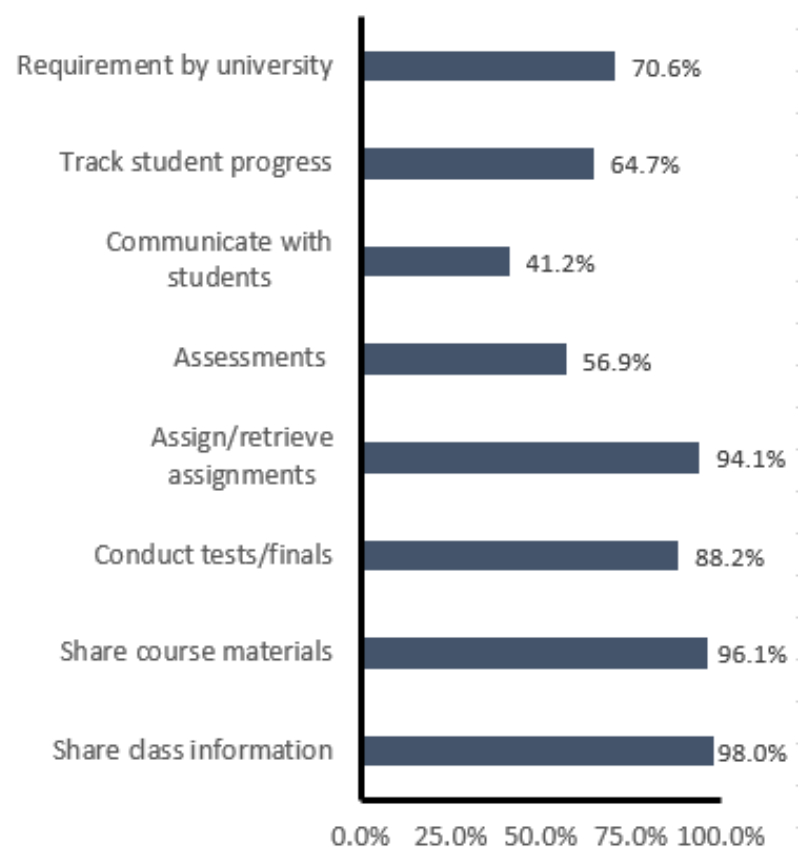

Figure 4. Purposes of using LMS in open and distance learning (ODL) activities.

Conducting tests and carrying out final examinations using LMS also rank amongst the top choices by the respondents (88.1\%). This is due to the fact that through LMS, tests/finals can be implemented either through synchronous or a synchronous approach which indeed very handy for the academician for ODL. There is an attractive feature in LMS platform where it enables one to automatically add up student cumulative course work marks (Kraleva et al., 2019). This is truly a useful feature for lecturers to track student progress throughout the semester but our data indicated that only few $(\sim 64.7 \%)$ exploited this function. Lack of training and unaware about such feature could probably be the reason why many didn't use LMS for that purpose. Some i.e. about $70.6 \%$ of the academician believed that they are only using LMS simply to comply with the university job requirement. Moreover, results in Figure 4 also indicated that LMS is probably not the best medium in assessment (56.9\%) and communication with students (41.2\%) for our academician. Communication is probably best executed via WhatsApp medium as it is easy and student questions can be attended to instantaneously. As for assessment especially student assignment and tests, it is most likely because lecturers still prefer to do it manually. Having it done online is not so straight forward and also because in higher learning engineering courses many of the examination questions are subjective that requires a thorough assessment on every solution/step provided. Results of this study is in agreement with some of the published works (AlHunaiyyan et al., 2020) where LMS is mainly used for administration of course work while interactive features such as chatroom, forum discussion, etc. are rarely applied.

\section{Issues associated to LMS for assessment of ODL}

Assessment is a procedure of obtaining information on the student achievement/knowledge based on what they have learnt or gained in the course they are attending. Generally, there are two types of assessment; namely formative and summative. Formative assessment is an on-going assessment during the lesson merely to evaluate how well students are learning the course materials. On the contrary, summative assessment is a measure of student understanding in the end of the course - typically this is done through the final examination (Singh and Thurman, 2019). Both are equally important elements in handling ODL as it measures the student progress and also as an indicator for lecturers to make any necessary changes in improving the student centred learning process they are implementing in the course. Creating such online assessment in ODL is indeed a challenging task. It can either be a quick assessment via online quizzes (or tests), online polls, direct feedback and reflections, or through game-type activities of which all can be implemented using various LMS platform. Figure 5 presents the preferences of the participants on the type of LMS for assessment of ODL.

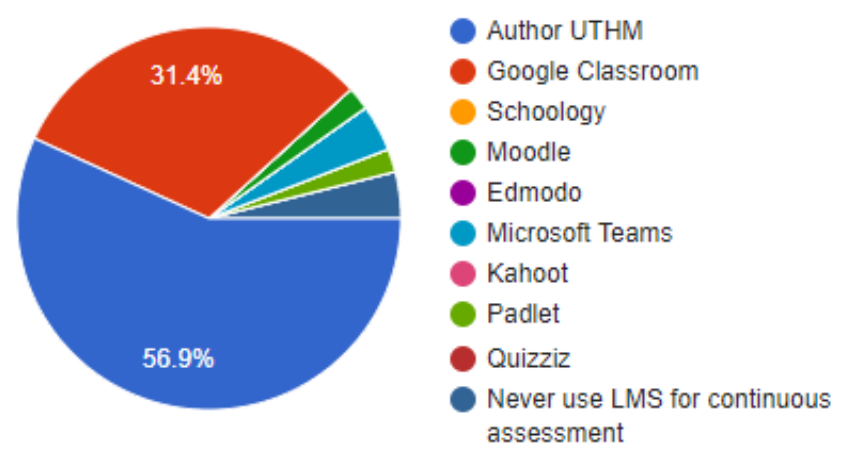

Figure 5. Preferences on type of LMS for assessment of ODL.

According to the data, similar trend as in preferences for teaching and learning activities is observed. Nearly two-third i.e. about $56.9 \%$ of our academic staff preferred to use Author UTHM medium for assessment. Utilization of Google Classroom ranks second at $31.4 \%$ and followed by Microsoft Teams. It is presumed that the choices were made based on the type of assessment that lecturers usually applied in their ODL session i.e. online quizzes and tests. Both approach are relatively easy to implement on line and suitable to measure learning results regardless the size of the class. Other medium such as Kahoot, Moodie, Edmundo, etc. are less favourable. Although such LMS is considered 'fun' and not 'test like' endeavours, 
lecturers do need to explore it first (probably on their own) and design it accordingly to get a proper feedback from the students. Else, students would merely be playing games rather than providing info on their level of understanding. Furthermore, lack of training and support from the institute could also be another reason that hinders lecturers from applying such game-based LMS in their ODL session.

Our argument is confirmed through the choices made by our academician on the type of online assessment they would implement in ODL using LMS (Figure 6). In this questionnaire, respondents were required to select the type online assessment of their own preferences for ODL using LMS platform. They were required to rank their choices in accordance to most preferred (rank 3), neutral/uncertain (rank 2) and least preferred (rank 1). It was found that majority (i.e. $>35$ staff out of 51) of the academician in our faculty preferred to use LMS only for various types of assessments. These include online test, individual and/or group assignment and projects. Moreover, these assessments are mostly open-ended type of evaluation where it is aimed to test student understanding on their theoretical knowledge. Openended questions are much more suitable for engineering courses in higher learning as it allows lecturers to design each questions according to the learning objectives they wanted to achieve (most likely student cognitive abilities).
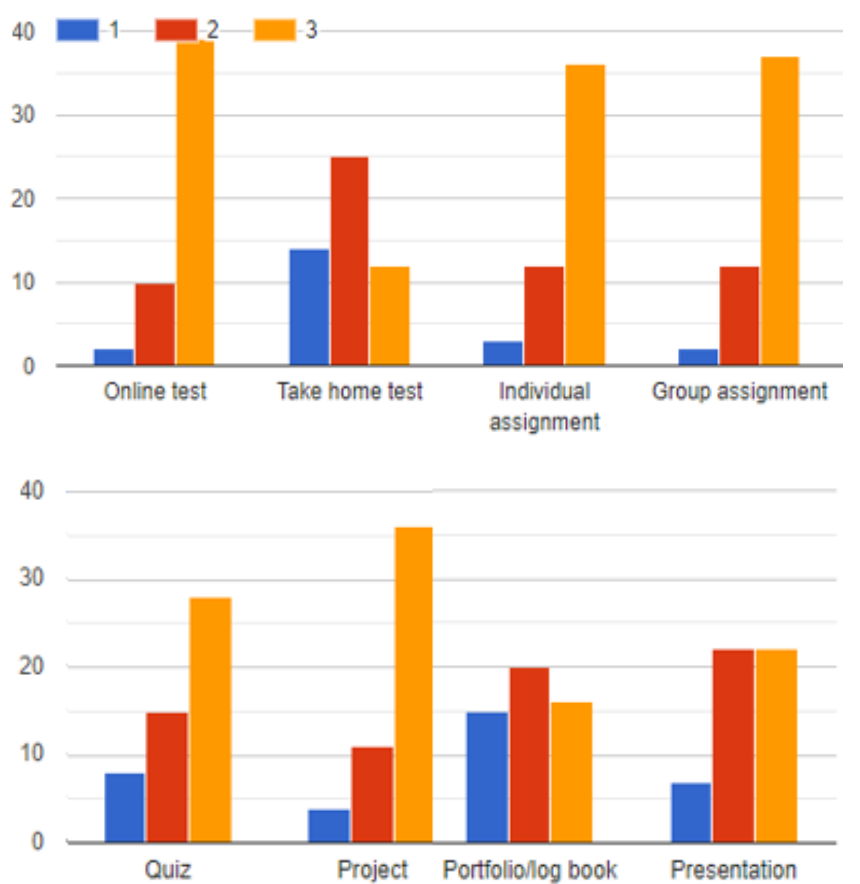

Figure 6. Respondent's choices on the type of online assessment for ODL using LMS platform.

Figure 7 highlights the respondent's perception on issues in using LMS for assessment of their ODL activities. From the results, inability to detect plagiarism or academic dishonesty during tests/finals ranked first with $35.3 \%$. Academic dishonesty is generally refer to cheating or exam frauds which is something that is rather difficult to detect in online environment. Students could easily copied information from the internet or exchange theirs answers with their classmates unnoticeable. In this scenario, lecturers could only give the students the benefit of the doubt and constantly remind them about academic integrities. Alternatively, lecturers could prepare different version of the same tests and carry out vetting procedure of the test questions to check for its suitability for online examination environment. Moreover, lecturers should ask everyone to turn on their web cameras and set a time limit in answering each questions given such that student would focus more on finding the solution to the problems given rather than to find ways to share it with their friends. Finally, in order to check academic integrity within answers submitted by the students, lecturers could use turnitin software where such software enabled lecturers to assess similarities of each test answers submitted.

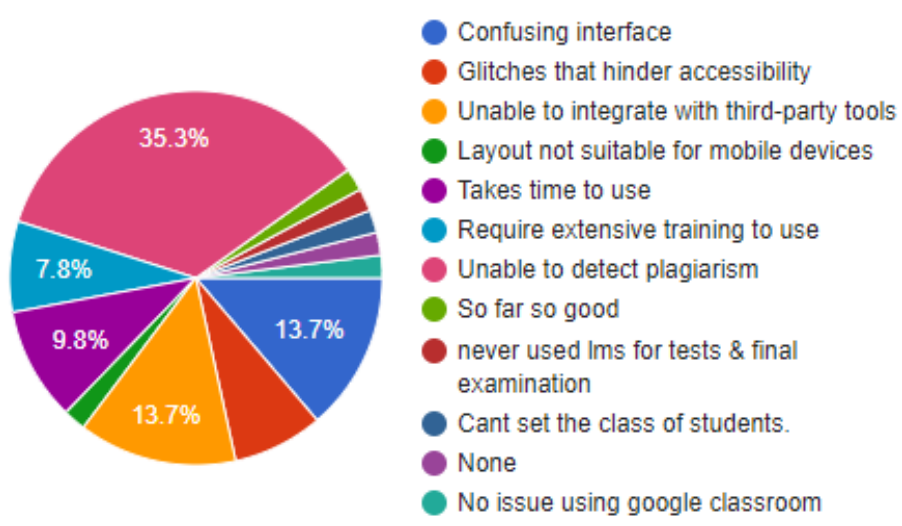

Figure 7. Issues experienced by respondents in using LMS for assessment.

Another pressing issue is inability to integrate with third-part tools (compatibility issues) and confusing LMS interface where both ranked second with $13.7 \%$. Compatibility issues would in fact limited the type of LMS functions for the lecturers. Furthermore, if technical support are not provided at times of need, lecturers would probably give up and stop using such LMS medium. Confusing interface is also troublesome especially if one could not locate the right icon on the dashboard and/or if the LMS contains many broken links. This usually happen to LMS with poor interface and indeed demoralized lecturers. Other main concerns associated to the use of LMS for assessment of ODL activities as experienced by our participants include the need for extensive trainings (7.8\%) and the amount of time that one needed to spend while using LMS (9.8\%). It is suspected that lack of practice (or motivation) and support from expert users amongst the faculty members could probably be the main reason for this. This issue can be overcome through a proper training programs and continuous support from the management to all academician about the use of LMS for ODL sessions. 


\section{Conclusion}

The paper aimed at evaluating preferred learning management system (LMS) for open and distance learning (ODL) of engineering courses. The study was conducted in Faculty of Mechanical and Manufacturing Engineering, Universiti Tun Hussein Onn Malaysia (UTHM) using online questionnaires. Based on the results of the survey, it can be concluded that many has already familiarized with such LMS platform for open and distance learning where majority collectively agreed that LMS is mainly used for course administration purposes. These include exchange/sharing or course materials and for continuous assessment of student progress. Participants reported that the main issue in using LMS for ODL is inability to detect plagiarism during online assessment. Other concerns are not as critical and are solvable through series of training programs. Encouraging lecturers to continuously explore and actively use LMS in their ODL activities is indeed essential as it is considered as part of the effort in improving lecturers skill set in online teaching.

\section{Acknowledgement}

We would like to express our gratitude and thanks to all academic staff of Faculty of Mechanical and Manufacturing Engineering, Universiti Tun Hussein Onn Malaysia (UTHM) for their dedication and participation in this study.

\section{References}

Aldiab, A., Chowdhury, H., Kootsookos, A., Alam, F., Allhibi, H. 2019. Utilization of Learning Management Systems (LMSs) in higher education system: A case review for Saudi Arabia. Energy Procedia, vol 160. 731-737.

Al-Hunaiyyan, H., Al-Sharhan, S., Aljahri, R. 2020. Prospect and Challenges of Learning Management Systems in Higher Education. International Journal of Advance Computer Science and Applications. vol 11(12). 73-79.

Alshira, M., Al-omari, M., Igried, B. 2021. Usability Evaluation of Learning Management Systems (LMS) based on User Experience. Turkish Journal of Computer and Mathematics Education (TURCOMAT). vol 12(11). 64316441.

Chung, C. 2013. Web-based Learning Management System Considerations for Higher Education. Learning and Performance Quarterly. vol 1(4). 24-37.

Chung, E., Noor, N. M., Vloreen Nity Mathew. 2020. Are you ready? an assessment of online learning readiness among university students. International Journal of Academic Research in Progressive Education and Development. vol 9(1).301-317.

Fashina, T., Adisa, O. I. 2020. Perception and Readiness Towards Integration of Learning Management System (LMS) Into Open and Distance Education. In Paper Knowledge . Toward a Media History of Documents (Issue March, 1226).

Irfan, M., Kusumaningrum, B., Yulia, Y., Widodo, S. A. 2020. Challenges During the Pandemic: Use of E-Learning in Mathematics Learning in Higher Education. Infinity Journal, vol 9(2). 147-158.

Ismail, N. S., Bakar, N. M. A., Wafa, S. W. 2020. Online Learning Challenges during Pandemic COVID-19 in Malaysian
Higher Learning Institution. Universal Journal of Educational Research. vol 8(12). 7151-7159.

Kraleva, R., Sabani, M., Kralev, V. 2019. An Analysis of Some Learning Management Systems. International Journal on Advanced Science, Engineering and Information Technology, vol 9. No. 4 ISSN: 2088-5334, 2019.

Lubiński, K., D.K. Tama, 2021. The observed effects of distance learning on curriculum implementation in management and business studies. Procedia Computer Science. vol 192. 2540-2549.

Mathew, V. N., Chung, E. 2020. University Students' Perspectives on Open and Distance Learning (ODL) Implementation Amidst COVID-19. Asian Journal of University Education. vol 16(4). 152-160.

Musa, A. H., Rosle, A. N., Baharuddin, F. N., Ibrahim, S. S. 2020. The Effectiveness of Online Distance Learning (ODL) Approach in University: A Respond of Covid-19 Pandemic Crisis. International Journal of Academic Research in Business and Social Sciences. vol 10(9). 1069-1076.

Okmawati, M. 2020. The Use of Google Classroom during Pandemic. Journal of English Language Teaching. vol9(2), 438. https://doi.org/ 10.24036/ jelt.v9i2.109293.

Saidi, R. M., Sharip, A. A., Abd Rahim, N. Z., Zulkifli, Z. A., Md Zain, S. M. 2021. Evaluating Students' Preferences of Open and Distance Learning (ODL) Tools. Procedia Computer Science. vol 179. 955-961.

Sanudin, R., Sahdan, M.Z., MOhd Tawil, S.N., Ruslan S.H. 2019. Assessment using e-learning Platform in UTHM. $1^{\text {st }}$ International Malaysian Educational Technology Convention. 149-156.

Selvanathan, M., Hussin, N. A. M., Azazi, N. A. N. 2020. Students learning experiences during COVID-19: Work from home period in Malaysian Higher Learning Institutions. Teaching Public Administration. https://doi.org/10.1177/0144739420977900.

Simamora, R. M., De Fretes, D., Purba, E. D., Pasaribu, D. 2020. Practices, Challenges, and Prospects of Online Learning during Covid-19 Pandemic in Higher Education: Lecturer Perspectives. Studies in Learning and Teaching. vol 1(3). 185-208.

Simanjuntak, D. C., Panjaitan, N. B. 2021. The inevitable surge of online learning through the lens of English education lecturers during the unprecedented times. Journal on English as a Foreign Language. vol 11(2). 358-380.

Singh, V., Thurman, A. 2019. How Many Ways Can We Define Online Learning? A Systematic Literature Review of Definitions of Online Learning (1988-2018). American Journal of Distance Education. vol 33(4). 289-306.

Uziak, J., Oladiran, T., Lorencowicz, E., Becker, K. 2018. Students' and Instructor's Perspective on the use of Blackboard Platform for Delivering an Engineering Course. The Electronic Journal of e-Learning. vol 16(1). 1-15.

Yusoff, S. A. M., Kadar, R., Mohamad, W. A. W., Mydin, A., \& Abdullah, M. H. 2021. The Impact of WhatsApp as an Instructional Tool for Online Distance Teaching and Learning (ODL). International Journal of Academic Research in Progressive Education and Development. vol 10(2). 585-595.

Zainal Alam, M.N.H. 2020. Arduino for Chemical Engineering Students via Game-based Learning. ASEAN Journal of Engineering Education. vol 4(1). 19-29.

Zainal Alam, M.N.H, Zakaria, Z.Y. 2021. Application of Computational Tools to support Cooperative Learning in Bioreactor Design Course. International Journal: Emerging Technologies in Learning. vol 16(15). 46-61. 